\title{
A Study of Association of Insulin Resistance with Preeclampsia
}

\author{
Lakshmi Prabha S. ${ }^{1}$, Shanmuga Priya V. ${ }^{2}$, Suganthy K. ${ }^{3}$, Kalaiselvi K. ${ }^{4}$ \\ ${ }^{1}$ Department of Biochemistry, VMMC\&H, Karaikal, Puducherry, India. ${ }^{2}$ Department of Biochemistry, \\ VMMC\&H, Karaikal, Puducherry, India. ${ }^{3}$ Department of Biochemistry, Vellammal Medial College, Madurai, \\ Tamilnadu, India. ${ }^{4}$ Department of Biochemistry, VMMC\&H, Karaikal, Puducherry, India.
}

\section{ABSTRACT}

\section{BACKGROUND}

Preeclampsia is one of the leading causes of morbidity and mortality in pregnant women, if not attended. Numerous methods have been used to predict the onset of preeclampsia with different degrees of accuracy. These methods used included foetal, placental and maternal markers in different stages of pregnancy. Our study attempts to find out if there is an association between preeclampsia and Insulin resistance, and whether insulin resistance can be used as a biomarker for diagnosis of preeclampsia.

\section{METHODS}

This study was performed among one hundred pregnant women of age ranging between 18-35 years and having gestational age between 28 to 34 weeks. Around 200 of them were screened for preeclampsia. Fifty obstetric patients identified as having preeclampsia were included in the study as cases. Fifty healthy pregnant subjects having uncomplicated pregnancies and who have been normotensive throughout gestation were taken as controls (total 100). Whole blood samples and 24 hour urine samples were collected. Serum was used for estimation of glucose and plasma for insulin concentrations. 24 hour urinary protein was measured. Insulin resistance was calculated by HOMA-IR method.

\section{RESULTS}

The mean value of fasting blood glucose in preeclamptic women is $87.27 \pm 7.36 \mathrm{mg} / \mathrm{dl}$ and that in control is $75.3 \pm 12.02 \mathrm{mg} / \mathrm{dl}$ and is statistically significant ( $\mathrm{p}=0.0548$ ) The mean value of plasma insulin in preeclamptic women is $57.27 \pm 7.1 \mu \mathrm{IU} / \mathrm{ml}$ and that in control is $26.43 \pm 4.23 \mu \mathrm{IU} / \mathrm{ml}$ and is statistically very significant ( $\mathrm{p}=0.0005$ ). The mean value of insulin resistance in preeclamptic women is $12.46 \pm 2.61$ and that in control is $5.69 \pm 2.14$ and is statistically very significant $(p=0.0005)$.

\section{CONCLUSIONS}

Insulin resistance can be used as a biomarker in diagnosis of preeclampsia.
Corresponding Author: Dr. Lakshmi Prabha S., Associate Professor, Department of Biochemistry, VMMC\&H, Karaikal-609609, Puducherry, India. E-mail:agathiarlakshmi@gmail.com

DOI: $10.14260 / j e m d s / 2020 / 119$

Financial or Other Competing Interests: None.

How to Cite This Article: Prabha LS, Priya SV, Suganthy K, et al. A study of association of insulin resistance with preeclampsia. J. Evolution Med. Dent. Sci.2020;9(08):527-531, 10.14260/jemds/2020/119

Submission 05-12-2019, Peer Review 29-01-2020, Acceptance 05-02-2020, Published 24-02-2020.

\section{(i)}

KEY WORDS

Preeclampsia, Insulin Resistance, Biomarker 


\section{BACKGROUND}

Preeclampsia is a multisystem disorder of unknown aetiology, characterized by development of hypertension to the extent of $140 / 90 \mathrm{~mm} \mathrm{Hg}$ or more with proteinuria and generalized oedema, after $20^{\text {th }}$ week of pregnancy in a previously normotensive and non-proteinuric women and resolves on delivery. ${ }^{\mathbf{1}}$ It contributes significantly to maternal and perinatal morbidity and mortality.

\section{Recent Definitions of Preeclampsia ${ }^{2}$}

The international society for the study of hypertension in pregnancy (ISSHP) has given following definitions for severe and early onset preeclampsia: Severe preeclampsia is defined by a systolic blood pressure $>160 \mathrm{mmHg}$ or diastolic blood pressure $>110 \mathrm{mmHg}$, with the presence of proteinuria (protein creatinine ratio in spot urine $>30 \mathrm{mg} / \mathrm{mmoles}$ of creatinine). The degree of proteinuria does not reflect the severity of the disease. According to ISSHP, early onset preeclampsia commences before 34 weeks of gestation. The American college of obstetrics and gynaecology (ACOG) defines preeclampsia similar to ISSHP, as far as blood pressure criteria is concerned, but differs from it in not including proteinuria, instead it includes the presence of any of the following: impaired liver function, thrombocytopenia, renal insufficiency, pulmonary oedema or new onset visual or cerebral disturbances.

\section{Diagnostic Criteria ${ }^{3}$}

Hypertension- Blood Pressure $\geq 140 / 90 \mathrm{mmHg}$ or a raise in systolic pressure of at least $30 \mathrm{~mm} \mathrm{Hg}$ or a raise in diastolic pressure of at least $15 \mathrm{~mm} \mathrm{Hg}$ over the base line, on at least two occasions, six hours apart.

Proteinuria- 24-hour urinary total protein $\geq 0.3 \mathrm{~g}$ or $\geq 2+(1$ $\mathrm{g} / \mathrm{L}$ ) on two random urine samples 4 hours apart.

Oedema- Pitting oedema over the ankles after 12 hours of bed rest and rapid gain in weight of more than $1 \mathrm{lb}$ a week or more than 5lb a month.

\section{Incidence $^{4}$}

The incidence of preeclampsia varies from $5-15 \%$.

\section{Eclampsia ${ }^{1}$}

Preeclampsia complicated with convulsions and/or coma, not attributed to other causes is called eclampsia.

\section{Insulin Resistance in Preeclampsia}

Insulin resistance is defined as the impaired ability of insulin to stimulate the uptake and utilization of glucose by muscle cells. ${ }^{5}$. When insulin resistance occurs, the normal amount of insulin secreted is not enough to deliver glucose into the cells. As a result pancreas increases its production of insulin to deliver blood sugar into the cells, causing hyperinsulinemia. Obesity, Diabetes mellitus and Pregnancy are some of the factors that cause insulin resistance. Insulin resistance is slightly raised in pregnant women, when compared to nonpregnant women. Hyper insulinemia and highly increased insulin resistance are seen in preeclampsia. ${ }^{6}$ Thus, increase in insulin resistance can be used as a marker for preeclampsia.

With the present diagnostic criteria used to identify preeclampsia, the disease can be diagnosed only after the full- blown manifestation of the condition. The routine parameters used such as blood pressure measurements, Doppler ultrasound technique, 24-hour urinary protein measurement etc. have certain limitations. Therefore, it has become important to identify suitable biomarkers for diagnosing preeclampsia. Genetic markers which can be more accurate are still costly in our country. Measurement of serum glucose as well as plasma insulin is relatively time and cost effective. Therefore calculation of insulin resistance and establishing its association with preeclampsia has become important in the diagnosis of preeclampsia.

\section{Aims and Objectives}

- To measure the level of plasma insulin and serum glucose of Preeclamptic women and normal healthy pregnant women in the third trimester.

- To estimate the frequency of Insulin resistance.

- To compare the level of insulin resistance between preeclamptic women and normal healthy pregnant women in the third trimester.

\section{METHODS}

The present research project is of analytical cross sectional study. The study was conducted in the department of Biochemistry, Vinayaka mission's Medical College, Karaikal. All trimester pregnant women, > 24 weeks, attending the Vinayaka mission's Medical College \& Hospital, Karaikal constituted the study population. 500 of them were screened for preeclampsia, Study was performed on one hundred pregnant women of age ranging between 18-35 years and having gestational age between, 28 to 34 weeks, out of which, 50 cases with the inclusion criteria mentioned earlier were taken as cases. 50 normal healthy third trimester pregnant women were taken as controls I. A brief clinical history of the subject was taken and systematic examination including weight, height and pulse rate was done. Blood pressure was recorded on two occasions, 6 hours apart. BMI was calculated. The information obtained was recorded in a structured protocol (a proforma was prepared for the same).

\section{IEC Approval and Informed Consent}

The present proposal was presented in front of ethical committee members of Vinayaka mission's Medical College, Karaikal, and approval was obtained. Signed consent was obtained from all the participants in a structured format, after explaining about the study in local language.

\section{Inclusion Criteria}

Hypertension- Blood Pressure $\geq 140 / 90 \mathrm{mmHg}$ or raise in systolic pressure of at least $30 \mathrm{mmHg}$ or a raise in diastolic pressure of at least $15 \mathrm{mmHg}$ over the base line, on at least two occasions, six hours apart in third trimester pregnant women.

Oedema- Pitting oedema over the ankles after 12 hours of bed rest and rapid gain in weight of more than $1 \mathrm{lb}$ a week or more than 5lb a month.

Proteinuria- Total protein in 24-hour urine $\geq 0.3 \mathrm{~g}$ or $\geq 2+$ (1 $\mathrm{g} / \mathrm{L}$ ) on two random samples 4 hours apart. 


\section{Exclusion Criteria}

- Fasting blood sugar over $110 \mathrm{mg} / \mathrm{dl}$.

- Hypertension over 140/90 mm Hg before 20 weeks of pregnancy.

- Hypertension without proteinuria in third trimester pregnant women.

- History of essential hypertension, renal disease, diabetes and heart disease.

- $\quad$ BMI over $25 \mathrm{Kg} / \mathrm{m}^{2}$

\section{Collection of Blood Sample and Urine Sample}

$5 \mathrm{ml}$ of venous blood sample was collected after overnight fasting. $3 \mathrm{ml}$ of blood was placed in EDTA vacutainers. Plasma was separated and used for estimation of insulin. $2 \mathrm{ml}$ of blood was placed in serum vacutainers. After retraction of the clot, the sample was centrifuged to collect serum and was used for estimation of Glucose. 24 hour urine sample was collected for the estimation of protein.

\section{Analysis of Blood Samples}

The blood samples collected as above was analysed for the estimation of following biochemical parameters using Semi auto analyser (bio Systems- BTS 350) and ELISA Reader (lab Life - ER 2007).

\section{Estimated Biochemical Parameters}

- Serum Glucose - Glucose Oxidase Peroxidase colorimetric endpoint method. 7

- Plasma Insulin - Enzyme Amplified Sensitivity Immuno Assay (INS - EASIA) ${ }^{8}$

- Urine - Urinary protein (pyrogallol Red colorimetric endpoint method) 9

\section{Calculated Parameter}

Body mass index $(\mathrm{BMI})=$ Weight in Kilogram $/$ Height in $\mathrm{m}^{2}$ Insulin resistance will be calculated by the Homeostasis Model Assessment Insulin Resistance score (HOMA-IR)

HOMA-IR= Fasting glucose $($ mmoles $/ \mathrm{L}) \times$ Fasting Insulin $(\mu \mathrm{IU} / \mathrm{ml}) / 22.5^{10,11}$

\section{Statistical Analysis}

The data obtained was entered systematically in MS Excel sheet. Statistical analysis was done using SPSS version. 16. Average, standard deviation and Student's t-test were done and p-value was calculated to verify the significance of the data.

\section{RESULTS}

From table 1, the average age of preeclamptic women is 25.23 \pm 3.58 years and that of normal pregnant women is $25.17 \pm$ 3.16 . The pulse rate in preeclamptic women is $83.67 \pm 2.63$ per minute and that in control group is $2.80 \pm 2.68$ per minute. BMI in preeclamptic women is slightly higher than the control group, but is not statistically significant. The mean \pm SD of BMI in preeclamptic women is $28.25 \pm 2.68$ and that in control is $25.85 \pm 2.76$. As shown in table 2 , the mean systolic blood pressure of preeclamptic women is $151.87 \pm 7.01 \mathrm{mmHg}$ and that of control is $112.00 \pm 5.50 \mathrm{mmHg}$ and is statistically very significant $(\mathrm{p}=0.0074)$. The mean diastolic blood pressure of preeclamptic women is $106.17 \pm 7.27 \mathrm{mmHg}$ and that of control is $75.00 \pm 7.30 \mathrm{mmHg}$.

\begin{tabular}{|c|c|c|}
\hline Parameters & Cases (Mean \pm SD) & Controls (Mean \pm SD) \\
\hline Age (years) & $25.23 \pm 3.58$ & $25.17 \pm 3.16$ \\
\hline Pulse/minute & $83.67 \pm 2.63$ & $82.80 \pm 2.68$ \\
\hline BMI (Kg/Sq.m) & $28.25 \pm 2.68$ & $25.85 \pm 2.76$ \\
\hline \multicolumn{2}{|r|}{ Table 1. Comparison of Age, Pulse and BMI in } \\
Preeclamptic Cases and Controls \\
\hline
\end{tabular}

\begin{tabular}{|c|c|c|c|c|}
\hline Clinical Parameters & $\begin{array}{c}\text { Cases } \\
(\text { Mean } \pm \text { SD) }\end{array}$ & $\begin{array}{c}\text { Controls } \\
(\text { Mean } \pm \text { SD) }\end{array}$ & t-Value & p-Value \\
\hline $\begin{array}{c}\text { Systolic blood pressure } \\
\text { (mmHg) }\end{array}$ & $151.87 \pm 7.01$ & $112.00 \pm 5.50$ & 2.774 & 0.0074 \\
\hline $\begin{array}{c}\text { Diastolic pressure } \\
\text { (mmHg) }\end{array}$ & $106.17 \pm 7.27$ & $75.00 \pm 7.30$ & 1.215 & $0.2292(\mathrm{NS})$ \\
\hline \multicolumn{4}{|c|}{ Table 2. Comparison of Systolic and Diastolic Blood Pressures } \\
In Pre-eclamptic Cases and Controls \\
\hline NS - Non significant
\end{tabular}

\begin{tabular}{|c|c|c|c|c|}
\hline $\begin{array}{c}\text { Biochemical } \\
\text { Parameter }\end{array}$ & $\begin{array}{c}\text { Cases } \\
(\text { Mean } \pm \text { SD) }\end{array}$ & $\begin{array}{c}\text { Controls } \\
(\text { Mean } \pm \text { SD) }\end{array}$ & t-Value & p-Value \\
\hline $\begin{array}{c}24 \text { hour Urinary } \\
\text { protein (g/day) }\end{array}$ & $4.87 \pm 1.61$ & $0.11 \pm 0.06$ & 4.0478 & 0.0002 \\
\hline \multicolumn{6}{|c|}{ Table 3. Comparison of Urinary Protein in } \\
Preeclamptic Cases and Controls \\
\hline
\end{tabular}

\begin{tabular}{|c|c|c|c|c|}
\hline Biochemical Parameter & $\begin{array}{c}\text { Cases } \\
(\text { Mean } \pm \text { SD) }\end{array}$ & $\begin{array}{c}\text { Controls } \\
(\text { Mean } \pm \text { SD) }\end{array}$ & $\begin{array}{c}\text { t- } \\
\text { Value }\end{array}$ & p-Value \\
\hline Fasting blood glucose $(\mathrm{mg} / \mathrm{dl})$ & $87.27 \pm 7.36$ & $75.3 \pm 12.02$ & 1.9593 & 0.0548 \\
\hline Plasma Insulin $(\mu \mathrm{IU} / \mathrm{ml})$ & $57.27 \pm 7.1$ & $26.43 \pm 4.23$ & 3.678 & 0.0005 \\
\hline Insulin resistance $(\mathrm{HOMA}-\mathrm{IR})$ & $12.46 \pm 2.61$ & $5.69 \pm 2.14$ & 8.639 & 0.0001 \\
\hline $\begin{array}{r}\text { Table 4. Comparison of Fasting Blood Glucose, Plasma Insulin and } \\
\text { Insulin Resistance in Preeclamptic Cases and Controls }\end{array}$ \\
\hline
\end{tabular}

\begin{tabular}{|c|c|c|}
\hline Parameter & r-Value & p-Value \\
\hline Systolic BP & 0.9758 & 0.0001 \\
\hline Diastolic BP & 0.4785 & 0.0001 \\
\hline Fasting blood glucose & 0.9929 & 0.0001 \\
\hline \multicolumn{2}{|c|}{ Table 5. Correlation of Insulin Resistance with Systolic BP, } \\
Diastolic BP and Fasting Blood Glucose \\
\hline
\end{tabular}

As shown in table 3, 24-hour urinary protein in preeclamptic women is very much elevated compared to that of control. The mean value in preeclamptic women is $4.87 \pm$ $1.61 \mathrm{~g} /$ day and that in control is $0.11 \pm 0.06 \mathrm{~g} /$ day and is statistically very significant. As shown in table 4 , the mean value of fasting blood sugar in preeclamptic women is $87.27 \pm$ $7.36 \mathrm{mg} / \mathrm{dl}$ and that in control is $75.3 \pm 12.02 \mathrm{mg} / \mathrm{dl}$ and is statistically significant $(\mathrm{p}=0.0548)$. The mean value of plasma insulin in preeclamptic women is $57.27 \pm 7.1 \mu \mathrm{IU} / \mathrm{ml}$ and that in control is $26.43 \pm 4.23 \mu \mathrm{IU} / \mathrm{ml}$ and is statistically very significant $(\mathrm{p}=0.0005)$. The mean value of insulin resistance in preeclamptic women is $12.46 \pm 2.61$ and that in control is $5.69 \pm 2.14$ and is statistically very significant $(p=0.0005)$. As shown in table 5 , insulin resistance is directly proportional to systolic BP, with a r-value of 0.9758 and is statistically extremely significant $(\mathrm{p}=0.0001)$. Insulin resistance is directly proportional to diastolic BP, with a r-value of 0.4785 and is statistically extremely significant $(p=0.0001)$. Insulin resistance is directly proportional to fasting blood glucose, with a r-value of 0.9929 and is statistically extremely significant $(\mathrm{p}=0.0001)$.

\section{DISCUSSION}

Our study shows that there is not much difference in age and pulse rate between preeclamptic women and control. BMI is 
slightly elevated in preeclamptic women than in control, but it is not statistically significant. As per the definition of preeclampsia, systolic BP (>140 $\mathrm{mmHg}$ ) and diastolic BP (>90 $\mathrm{mmHg}$ ) are well elevated in preeclampsia than the controls where it is $<120 / 80$. Similarly, as per definition, 24-hour urinary protein should be $>300 \mathrm{mg} / \mathrm{d}$. In our study we observe that there is massive proteinuria similar to that in renal failure diseases. Fasting blood glucose falls under normal level $<110$ $\mathrm{mg} / \mathrm{dl}$ for both preeclamptic women and control. It should be remembered that gestational diabetes is an exclusion criterion in our study. Severe hyper insulinemia is observed in preeclamptic women, compared to that of control. But even normal healthy pregnant women have increased insulin level than the non-pregnant women. The optimal cut off of Homeostasis Model Assessment of Insulin Resistance (HOMAIR) is 1.775 for non-diabetic and 3.875 for diabetic and $2.1 \pm$ 0.9 in pregnant women. ${ }^{10,11}$

Cut-off for insulin resistance in non-pregnant women is 1.775 and that of pregnant women is $2.1 \pm 0.9$. In our study also, there is increased insulin resistance even in normal healthy pregnant women, who serve as control. In preeclamptic women IR is highly exaggerated, nearly twice as that of control. This suggests that insulin resistance can be very well be used as a biomarker in the diagnosis of preeclampsia. Thus, this study design and its results clearly support the hypothesis that "elevated insulin resistance is a biomarker for the diagnosis of preeclampsia". Also to support the above statement, the study shows that the insulin resistance has a positive correlation with both systolic BP and Diastolic BP, which is statistically very significant. It should be remembered that drugs taken to treat IR, also decreases the blood pressure. Insulin resistance also shows positive correlation with systolic blood pressure, which is statistically significant.

Parretti et al. have proposed the association of insulin resistance with preeclampsia. Also, they added that increased insulin resistance is observed in these pregnant women, well before the manifestation of the disease. ${ }^{12}$ Previous studies conducted showed similar results. A study conducted in Karnataka, India, by Sonagra et al showed that Insulin resistance was increased in preeclampsia women, compared to normal pregnant women, and as the disease advances, Insulin resistance increases. Also, there is increased risk of maternal and foetal complications in the presence of increased IR. ${ }^{13}$ In another study conducted, Ashuman Ghosh et al, reported that decrease in micro vascular blood flow were associated with elevations in anti-angiogenic mediators and is associated with elevation in insulin resistance in preeclamptic women. ${ }^{14}$ Elevated insulin resistance increases sympathetic tone and muscle blood flow, and may cause increased blood pressure. It has been observed that the drugs that reduce insulin resistance, such as, Thiazolidinediones, also decrease blood pressure. This suggests the association of insulin resistance with blood pressure. ${ }^{15}$

Hyperinsulinemia and increased insulin resistance are observed even in normal pregnant women, particularly in the third trimester. ${ }^{16}$ In preeclampsia there is an exaggeration of insulin resistance and associated metabolic changes. Hyperinsulinemia may directly predispose to hypertension by increased renal sodium reabsorption and stimulation of sympathetic nervous system ${ }^{3}$. In several studies conducted postpartum, women with a history of preeclampsia have been shown to be insulin resistant, with increased fasting insulin and glucose. In a study conducted in Nantang, China, Zhifang et al. ${ }^{17}$ Showed that HOMA-IR was increased, and HOMA-ISI was decreased in preeclampsia. In another study, Abhari et al. reported that Insulin resistance was higher in the first trimester, prior to diagnosis, as well as, in third trimester after diagnosis.

\section{CONCLUSIONS}

Elevated insulin resistance is strongly associated with occurrence of preeclampsia. Thus Insulin resistance can be used as a biomarker for diagnosis of preeclampsia.

\section{REFERENCES}

[1] Cunningham FG, Leveno KJ, Bloom SL, et al. Pregnancy hypertension. In: Cunningham FG, Lenovo KJ, Bloom SI, et al. eds. Williams Obstetrics. 23 rd edn. New York (NY): The McGraw-Hills Companies, 2010: p. 706-8.

[2] Phipps E, Prasanna D, Brima W, et al. Preeclampsia: updates in pathogenesis, definitions and guidelines. Clinical Journal of American Society of Nephrologist 2016;11(6):1102-13

[3] Roberts JM, Balk JL, Bodnar LM, et al. Nutrient involvement in preeclampsia. The Journal of Nutrition 2003;133(5 Suppl 2):1684s-92s.

[4] Taylor RN, Roberts JM, Cunningham FG, et al. Chesely's hypertensive disorders in pregnancy. $4^{\text {th }}$ edn. Kidlington, UK: Elsevier 2014: p. 37-57.

[5] Raeven G, Lithell H, Landsberg L. Hypertension and associated metabolic abnormalities - the role of insulin resistance and sympathoadrenal system. New England Journal of Medicine 1996;334(6):374-81.

[6] Abhari FR, Andarieh MG, Farokhfar A, et al. Estimating rate of insulin resistance in patients with preeclampsia using HOMA-IR index and comparison with nonpreeclampsia pregnant women. Article ID 140851, Biomed Research International 2014; 2014:1-6.

[7] Basak A. Development of rapid and inexpensive plasma glucose estimation by two-point kinetic method based on glucose oxidase-peroxidase enzyme. Indian Journal of Clinical Biochemistry 2007;22(1):156-60.

[8] Diaz-Lopez A, Bullo M, Juanola-Falgarona $M$, et al. Reduced serum concentrations of carboxylated and under carboxylated osteocalcin are associated with risk of developing type 2 diabetes mellitus in a high cardiovascular risk population: a nested case-control study. Journal of Clinical Endocrinology \& Metabolism 2013;98(11):4524-31.

[9] Burtis CA, Ashwood ER, Tietz NW. Tietz text book of Clinical chemistry. $3^{\text {rd }}$ edn. Philadelphia: WB Saunders Co., 1986.

[10] Esteghamati A, Ashraf H, Khalilzadeh O, et al. Optimal cutoff homeostasis model assessment of Insulin resistance (HOMA-IR) for the diagnosis of metabolic syndrome: Third national surveillance of risk factors of non- 
communicable diseases in Iran (SuRFNCD 2007). Nutrition and Metabolism (Lond) 2010;7(26):1-8.

[11] Jahromi AS, Zareian P, Madani A. Insulin resistance and interleukins- $1 \beta$ during normal pregnancy. Asian Journal of Biochemistry 2011;6(4):366-72.

[12] Parretti E, Lapolla A, Dalfra MG. Preeclampsia in lean normotensive pregnant women can be predicted by simple insulin sensitivity indexes. Hypertension 2006;47(3):449-53.

[13] Sonagra AD, Deba Z, Makandar A, et al. Study on insulin resistance in women with preeclampsia. Indian Journal of Medical Biochemistry 2017;21(2):127-30.

[14] Anshuman G, Nicholas SF, Anim-Nyame N, et al. Micro vascular function in pre-eclampsia is influenced by insulin resistance and an imbalance of angiogenic mediators. Physiological Reports 2017;5(8):e13185.

[15] Sonagra AD, Biradar SM, Dattatreya K, et al. Normal pregnancy-state of insulin resistance. Journal of Clinical Diagnosis \& Research 2014;8(11):CC01-CC03.

[16] Seely EW, Solomon CG. Insulin resistance and its potential role in pregnancy-induced hypertension. The Journal of Clinical Endocrinology \& Metabolism 2003;88(6):2393-8.

[17] Chen Z, Liu W, Sun X, et al. Clinical study on association between pregnancy-induced hypertension and Insulin resistance. Experimental \& Therapeutic Medicine 2017;13(5):2065-70. 